\title{
Characteristics and screening history of women diagnosed with cervical cancer aged 20-29 years
}

\author{
A Castanon ${ }^{*}, 1, \mathrm{~V}$ M W Leung ${ }^{1}, \mathrm{R}$ Landy $^{1}, \mathrm{~A}$ W W Lim ${ }^{1}$ and P Sasieni ${ }^{1}$ \\ ${ }^{1}$ Centre for Cancer Prevention, Wolfson Institute of Preventive Medicine, Queen Mary University of London, Charterhouse Square, \\ London, EC1M 6BQ, UK
}

Background: There was concern that failure to screen women aged 20-24 years would increase the number of cancers or advanced cancers in women aged 20-29 years. We describe the characteristics of women diagnosed with cervical cancer in England aged 20-29 years and examine the association between the period of diagnosis, screening history and FIGO stage.

Methods: We used data on 1800 women diagnosed with cervical cancer between April 2007 and March 2012 at age 20-29 from the National Audit of Invasive Cervical Cancers.

Results: The majority of cancers (995, or $62 \%$ of those with known stage) were stage $1 \mathrm{~A}$. Cancer at age 20-24 years was rare (12\% of those aged 20-29 years), when compared with age 25 (24\%) and age 26-29 years (63\%); however, cancers in women aged 20-24 years tended to be more advanced and were more often of a rare histological type. For 59\% of women under age 30 , the cervical cancer was screen detected, most of them (61\%) as a result of their first screening test. A three-fold increase in the number of cancers diagnosed at age 25 years was seen since the start of the study period.

Conclusion: Cervical cancer at age 20-24 years is rare. Most cancers in women under age 30 years are screen detected as microinvasive cancer.

\begin{abstract}
With the introduction of the cervical screening programme in 1988 it was hoped that cervical cancer could be almost eliminated, particularly in young women. In fact, the introduction of screening has not only prevented cancers but has also led to those cancers in screened women that are not prevented being diagnosed at much earlier stages. Because the lead time between the onset of earlystage occult cervical cancer and the development of symptoms can be considerable, screening has led to a shift in the peak incidence of cervical cancer (among women eligible for screening) from age 35-49 years in 1993-1995 to age 25-34 years in 2007-2009 (Cancer Research UK, 2010). In addition, cancer rates have steadily been increasing over the past 20 years in young women (Foley et al, 2011), possibly because of changes in the underlying rates of sexually transmitted infections including human papilloma virus (PHLS Communicable Disease Surveillance Centre, 2006a,b; Sargent et al, 2008).
\end{abstract}

There is increasing evidence that cervical screening in women aged 20-24 years is not as effective in preventing cervical cancer as screening women aged 25 +years (Sasieni et al, 2003, 2009). Therefore, in late 2003, a change in cervical screening policy was announced whereby women in England would first be invited at their 25th birthday instead of from age 20 years. There was concern among some that the change in policy would lead to an increase in cervical cancer and in particular to an increase in cancers diagnosed at more advanced stages (Herbert et al, 2008; Fiander, 2008).

The new policy was rolled out in 2004, but was not retrospective in that women already invited for screening before age 25 years would receive a second invitation 3 years later even if still under age 25 years. In addition, it took $\sim 15$ months to roll out the change in policy nationally. It was only from mid 2009 that substantial numbers of women would have received a first

*Correspondence: Dr A Castanon; E-mail: a.castanon@qmul.ac.uk

Received 12 April 2013; revised 4 June 2013; accepted 4 June 2013; published online 2 July 2013 
screening invitation at age 25 years. Thus, to see the full impact of the change to the screening policy, we will need to wait until the cohort of women first invited for screening at age 25 years (those born since 1984/1985) reach the age of 30 years.

At the May 2009 meeting of the Advisory Committee on Cervical Screening (ACCS), the change in the screening policy was re-examined, and recommendations were made to the National Cancer Director and Ministers. Both in the meeting and in the recommendations, an emphasis was placed on monitoring and surveillance, so that important changes in the incidence and/or the stage of cancer in women aged 20-29 years could be identified as soon as possible (Department of Health, 2010).

Here we aim to describe the characteristics of women who develop cervical cancer in their twenties in terms of stage at diagnosis, histology, treatment and socioeconomic status, and to examine changes in screening history by stage.

\section{MATERIALS AND METHODS}

Subjects. We used data on women in England diagnosed with cervical cancer (ICD-10 C53) aged 20-29.99 years between April 2007 and March 2012 from the National Audit of Invasive Cervical Cancers (October 2012 data set). The audit includes over $90 \%$ of all cancers diagnosed nationally. The screening histories of these women were abstracted from routinely recorded cervical cytology records held on the National Cervical Screening Call/Recall System, including all NHS and many private tests. Treatment details, FIGO stage at diagnosis and histological type are recorded as and when the data become available. As these data are collected from multiple sources, they are not as complete or accurate as the screening history data. Details of the audit have been published previously (Sasieni et al, 2003, 2009).

Statistical methods. Descriptive statistics were examined to compare the distributions of the International Federation of Gynaecology and Obstetrics (FIGO) staging system at diagnosis, histology, treatment, period of diagnosis, deprivation and screening history. $\chi^{2}$ tests were used to test for differences between the age groups.

Deprivation was measured using the index of multiple deprivation (IMD) (Department for Communities and Local Government, 2011), a composite measure of seven domains of deprivation, including income and employment. It is derived from each woman's postcode and divided into national deciles. We divided the women into three groups based on their IMD: the three most deprived deciles, the next three deciles and the four least deprived deciles. In two regions, IMD was not recorded. Consequently we included 'unknown' as a separate IMD category. Similarly, when histology, treatment or stage was unknown, a separate 'unknown' category was formed. These categories were ignored when testing for differences between age groups.

Rates were calculated using the ONS mid-year population estimates for the relevant years (Office for National Statistics, 2013).

Unfortunately, we are unable to ascertain if and when women were invited for a cytology test. This means that we are unable to distinguish women who attended as part of routine screening from women who attended because of symptoms. However, it is extremely unlikely that a woman could be diagnosed with cervical cancer within 14 days of a routine screen. It typically takes 14 days for a woman to receive the result of her screening test (and it used to take considerably longer); we therefore assume that any woman diagnosed within 14 days of a test was referred on the day the cytology was taken and that the result of the cytology had no influence on her pathway to diagnosis (Health and Social Care Information Centre, 2012).
In addition, the change in policy (from first inviting women at age 20 to age 25 years) occurred over a 15-month period, and hence it is not possible to determine whether women born between 26 August 1984 and 3 November 1985 were invited for screening from age 20 years or not. To assess the impact of the change in policy, we have divided the data set into three time periods of 20 months each. The first period ('mostly invited from 20') includes those diagnosed from April 2007 to November 2008; during this period, all women diagnosed at age 25-29 years would have been invited for screening at age 20 years. The middle period ('mixed') runs from December 2008 to July 2010; in this period, some of those women diagnosed aged 25 years were first invited at age 20 and some at 25 years. The final period ('mostly invited from 25') runs from August 2010 to March 2012, when almost all women diagnosed aged 25 years would have been first invited for screening at age 25 years. Note that none of the women diagnosed aged 20-21 years in this study were invited for screening before diagnosis, and all of those diagnosed at age 27-29 years should have been invited at age 20 years.

Delays in the registration of newly diagnosed cancers in our audit mean that the number of cases will be underreported, particularly in the most recent period. To adjust for this we have inflated the rates (but not the numbers) in the last period (August 2010 to March 2012). The inflation factor (13.9\%) is the proportion by which the number of cases aged 20-29 years diagnosed between August 2008 and March 2010 increased between the 2010 and the 2012 data sets. The inflation factor is generous and there is evidence that reporting into the audit is becoming timelier; over the period August 2009 to March 2011, the increase between the 2011 data set and the 2012 data set was $8.7 \%$ compared with $11.1 \%$ for the corresponding periods a year earlier.

We have classified the pathway to diagnosis for these women according to their screening history as follows (full details can be found in Appendix 1):

(1) Never screened or lapsed: women with no screening history (more than 14 days before diagnosis) other than possibly a single inadequate test; women $(N=23)$ whose last test resulted in routine recall and was over 3.5 years before diagnosis (the group labelled 'lapsed' in Appendix 1).

(2) Screen detected prevalent (on first test): women diagnosed within 4 months of cytology indicating referral to colposcopy. In addition, there should be no prior test resulting in routine recall, and if the first screening test resulted in early recall, the next test must be within 1 year.

(3) Screen detected incident: diagnosed between 2.75 and 3.5 years after a negative test. The interval following an early recall test (if any) must not exceed 1 year and they must have a cytology test indicating referral to colposcopy within 4 months of diagnosis.

(4) Screen detected lapsed: diagnosed $>3.5$ years after a negative test. Same definition as (3) above, but the women have a negative test $>3.5$ years before the abnormal test.

(5) Post abnormal: The interval following early recall tests (if any) exceeds 1 year and/or they are diagnosed more than 4 months after a cytology indicating referral to colposcopy or they have no suspends but they have a history of low-grade cytology resulting in early recall.

(6) Interval cancers: women diagnosed $<2.75$ years after a cytology test resulting in routine recall. Also includes women diagnosed between 2.75 and 3.5 years after a cytology test resulting in routine recall, but with no other tests before diagnosis, or women with their first early recall on the pathway to diagnosis 2.75-3.5 years after a cytology test resulting in routine recall, with no more than a year between an early recall and the following test or diagnosis. 


\section{RESULTS}

The study includes a total of 1800 women diagnosed with cervical cancer aged 20-29 years between April 2007 and March 2012. The majority of cancers (63.2\%) were diagnosed between the age of 26 and 29 years, with a further $24.4 \%$ diagnosed at age 25 years. Cervical cancer is rare in women aged 20-24 years compared with women aged $25-29$ years, with only $12.4 \%(n=223)$ of cancers diagnosed in this age group, which is roughly equivalent to the number of cancers diagnosed at age 26 years $(n=257)$. Furthermore, half $(n=110)$ of all cancers diagnosed at age $20-24$ years were diagnosed at age 24 years, $25 \%(n=56)$ at age 23 years and $26 \%(n=57)$ at age $20-22$ years.
Table 1 shows the characteristics of these women by age at diagnosis. Over $60 \%$ of cancers in this age group are diagnosed as stage $1 \mathrm{~A}$ and, across all stages, $69 \%$ are treated conservatively with fertility-sparing treatment (the proportion increases to $94 \%$ among those with stage $1 \mathrm{~A}$ cancer and known treatment). Cancers in women aged 20-24 years tend to be more advanced at diagnosis than those in older women: a higher proportion of women under age 25 years had stage 2 or worse cancer $(20 \%$ vs $6 \%, P<0.001)$, resulting in more women treated by chemotherapy and/or radiotherapy \pm hysterectomy ( $37 \%$ vs $14 \%, P<0.001)$ and a smaller proportion having fertility-sparing treatment (46\% vs $72 \%$, $P<0.001)$; a higher proportion were diagnosed with adenosquamous carcinoma and other rarer histological types (10\% vs $4 \%$, $P<0.001)$. No differences in socioeconomic status were observed

Table 1. Characteristics of women diagnosed with cervical cancer aged 20-29 years

\begin{tabular}{|c|c|c|c|c|c|c|c|c|}
\hline & \multicolumn{2}{|c|}{ Age 20-24 } & \multicolumn{2}{|c|}{ Age 25} & \multicolumn{2}{|c|}{ Age 26-29 } & \multicolumn{2}{|c|}{ All ages } \\
\hline & $\mathbf{N}$ & $\%$ & $\mathbf{N}$ & $\%$ & $\mathbf{N}$ & $\%$ & $\mathbf{N}$ & $\%$ \\
\hline \multicolumn{9}{|l|}{ Stage } \\
\hline $\begin{array}{l}1 \mathrm{~A} \\
1 \mathrm{~B} \\
2+ \\
\text { Unknown }\end{array}$ & $\begin{array}{l}77 \\
74 \\
38 \\
34\end{array}$ & $\begin{array}{c}40.7 \% \\
39.2 \% \\
20.1 \% \\
-\end{array}$ & $\begin{array}{c}293 \\
83 \\
15 \\
49\end{array}$ & $\begin{array}{c}74.9 \% \\
21.2 \% \\
3.8 \% \\
-\end{array}$ & $\begin{array}{c}625 \\
333 \\
77 \\
102\end{array}$ & $\begin{array}{c}60.4 \% \\
32.2 \% \\
7.4 \% \\
-\end{array}$ & $\begin{array}{l}995 \\
490 \\
130 \\
185\end{array}$ & $\begin{array}{c}61.6 \% \\
30.3 \% \\
8.0 \% \\
-\end{array}$ \\
\hline \multicolumn{9}{|l|}{ Histology } \\
\hline $\begin{array}{l}\text { Squamous } \\
\text { Adenocarcinoma } \\
\text { Adenosquamous } \\
\text { Other } \\
\text { Unknown }\end{array}$ & $\begin{array}{c}163 \\
32 \\
9 \\
12 \\
7\end{array}$ & $\begin{array}{c}75.5 \% \\
14.8 \% \\
4.2 \% \\
5.9 \% \\
-\end{array}$ & $\begin{array}{c}352 \\
55 \\
9 \\
9 \\
15\end{array}$ & $\begin{array}{c}82.8 \% \\
12.9 \% \\
2.1 \% \\
2.1 \% \\
-\end{array}$ & $\begin{array}{c}863 \\
186 \\
28 \\
15 \\
45\end{array}$ & $\begin{array}{c}79.0 \% \\
17.0 \% \\
2.6 \% \\
1.4 \% \\
-\end{array}$ & $\begin{array}{c}1378 \\
273 \\
46 \\
36 \\
67\end{array}$ & $\begin{array}{c}79.5 \% \\
15.8 \% \\
2.7 \% \\
2.1 \% \\
-\end{array}$ \\
\hline \multicolumn{9}{|l|}{ Treatment } \\
\hline $\begin{array}{l}\text { Cone biopsy or trachelectomy } \\
\text { Hysterectomy (simple or radical) } \\
\text { Chemotherapy and/or radiotherapy } \pm \text { hysterectomy } \\
\text { Unknown }\end{array}$ & $\begin{array}{l}71 \\
26 \\
58 \\
68\end{array}$ & $\begin{array}{l}45.8 \% \\
16.8 \% \\
37.4 \% \\
-\end{array}$ & $\begin{array}{c}227 \\
26 \\
29 \\
158\end{array}$ & $\begin{array}{c}80.5 \% \\
9.2 \% \\
10.3 \% \\
-\end{array}$ & $\begin{array}{l}560 \\
131 \\
119 \\
327\end{array}$ & $\begin{array}{l}69.1 \% \\
16.2 \% \\
14.7 \% \\
-\end{array}$ & $\begin{array}{l}858 \\
183 \\
206 \\
553\end{array}$ & $\begin{array}{c}68.8 \% \\
14.7 \% \\
16.5 \% \\
-\end{array}$ \\
\hline \multicolumn{9}{|l|}{ Period of diagnosis } \\
\hline $\begin{array}{l}\text { Diagnosed between April } 2007 \text { and November } 2008 \\
\text { Diagnosed between December } 2008 \text { and July } 2010 \\
\text { Diagnosed between August } 2010 \text { and March } 2012\end{array}$ & $\begin{array}{l}89 \\
77 \\
57\end{array}$ & $\begin{array}{l}39.9 \% \\
34.5 \% \\
25.6 \%\end{array}$ & $\begin{array}{c}68 \\
146 \\
226\end{array}$ & $\begin{array}{l}15.5 \% \\
33.2 \% \\
51.4 \%\end{array}$ & $\begin{array}{l}367 \\
455 \\
315\end{array}$ & $\begin{array}{l}32.3 \% \\
40.0 \% \\
27.7 \%\end{array}$ & $\begin{array}{l}524 \\
678 \\
598\end{array}$ & $\begin{array}{l}29.1 \% \\
37.7 \% \\
33.2 \%\end{array}$ \\
\hline \multicolumn{9}{|l|}{ Deprivation (in deciles) } \\
\hline $\begin{array}{l}0-2 \text {, most deprived } 30 \% \\
3-5 \\
6-9 \text {, least deprived } 40 \% \\
\text { Unknown }\end{array}$ & $\begin{array}{l}73 \\
56 \\
41 \\
53\end{array}$ & $\begin{array}{l}42.9 \% \\
32.9 \% \\
24.1 \%\end{array}$ & $\begin{array}{c}153 \\
101 \\
107 \\
79\end{array}$ & $\begin{array}{l}42.4 \% \\
28.0 \% \\
29.6 \%\end{array}$ & $\begin{array}{l}361 \\
274 \\
252 \\
250\end{array}$ & $\begin{array}{l}40.7 \% \\
30.9 \% \\
28.4 \%\end{array}$ & $\begin{array}{l}587 \\
431 \\
400 \\
382\end{array}$ & $\begin{array}{l}41.4 \% \\
30.4 \% \\
28.2 \%\end{array}$ \\
\hline \multicolumn{9}{|l|}{ Screening history } \\
\hline Never & 97 & $43.5 \%$ & 38 & $8.6 \%$ & 86 & $7.6 \%$ & 221 & $12.3 \%$ \\
\hline Interval & 7 & $3.1 \%$ & 13 & $3.0 \%$ & 101 & $8.9 \%$ & 121 & $6.7 \%$ \\
\hline $\begin{array}{l}\text { Screen detected } \\
\text { Prevalent (on first test) } \\
\text { Incident ( } 2.75-3.5 \text { years after negative) } \\
\text { Lapsed ( }>3.5 \text { years after negative) }\end{array}$ & $\begin{array}{c}72 \\
10 \\
6\end{array}$ & $\begin{array}{l}32.3 \% \\
4.5 \% \\
2.7 \%\end{array}$ & $\begin{array}{c}290 \\
5 \\
30\end{array}$ & $\begin{array}{l}65.9 \% \\
1.1 \% \\
6.8 \%\end{array}$ & $\begin{array}{l}277 \\
163 \\
199\end{array}$ & $\begin{array}{l}24.4 \% \\
14.3 \% \\
17.5 \%\end{array}$ & $\begin{array}{l}639 \\
178 \\
235\end{array}$ & $\begin{array}{c}35.5 \% \\
9.9 \% \\
13.1 \%\end{array}$ \\
\hline $\begin{array}{l}\text { Post abnormal } \\
\text { Time from abnormal to diagnosis }<1 \text { year } \\
\text { Time from abnormal to diagnosis } \geqslant 1 \text { year }\end{array}$ & $\begin{array}{l}18 \\
13\end{array}$ & $\begin{array}{l}8.1 \% \\
5.8 \%\end{array}$ & $\begin{array}{c}55 \\
9\end{array}$ & $\begin{array}{c}12.5 \% \\
2.0 \%\end{array}$ & $\begin{array}{l}152 \\
159\end{array}$ & $\begin{array}{l}13.4 \% \\
14.0 \%\end{array}$ & $\begin{array}{l}225 \\
181\end{array}$ & $\begin{array}{l}12.5 \% \\
10.1 \%\end{array}$ \\
\hline Total N & 223 & $100 \%$ & 440 & $100 \%$ & 1137 & $100 \%$ & 1800 & $100 \%$ \\
\hline
\end{tabular}



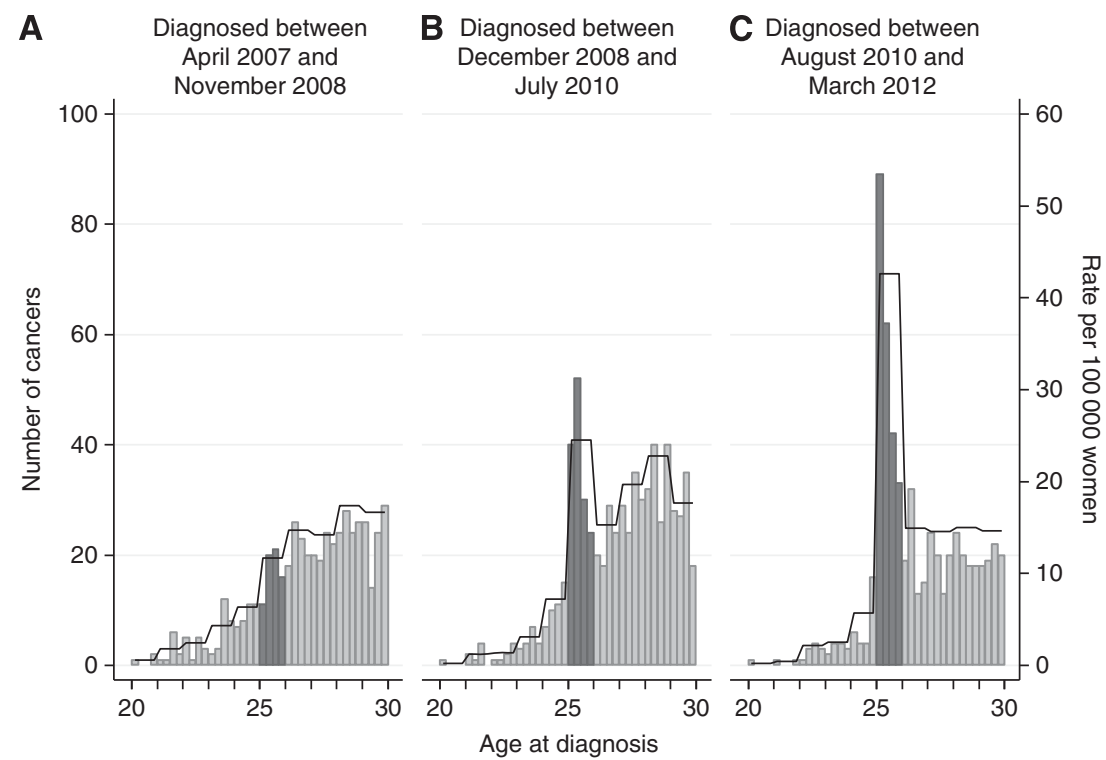

Figure 1. Rate and number of cancers in the study by age at diagnosis. (A) For those diagnosed between April 2007 and November 2008 , (B) for those diagnosed between December 2008 and July 2010, (C) for those diagnosed between August 2010 and March 2012. The darker shading indicates cancers diagnosed at age 25 .

\section{Table 2. International Federation of Gynaecology and Obstetrics (FIGO) stage by age and date of diagnosis}

\begin{tabular}{|l|l|c|c|c|c|c|c|c|c|}
\hline \multicolumn{2}{|c|}{} & \multicolumn{3}{|c|}{ 1A } & \multicolumn{3}{|c|}{ 1B } & \multicolumn{3}{|c|}{ Unknown } \\
\hline Age at diagnosis, years & Period of diagnosis & $\mathbf{N}$ & $\%$ & $\mathbf{N}$ & $\%$ & $\mathbf{N}$ & $\%$ & $\mathbf{N}$ & $\%$ \\
\hline $20-24$ & Apr 2007-Nov 2008 & 37 & $42 \%$ & 42 & $47 \%$ & 10 & $11 \%$ & 89 & $100 \%$ \\
& Dec 2008-Jul 2010 & 26 & $34 \%$ & 43 & $56 \%$ & 8 & $10 \%$ & 77 & $100 \%$ \\
& Aug 2010-Mar 2012 & 14 & $25 \%$ & 34 & $60 \%$ & 9 & $16 \%$ & 57 & $100 \%$ \\
\hline 25 & Apr 2007-Nov 2008 & 41 & $60 \%$ & 19 & $28 \%$ & 8 & $12 \%$ & 68 & $100 \%$ \\
& Dec 2008-Jul 2010 & 94 & $64 \%$ & 40 & $27 \%$ & 12 & $8 \%$ & 146 & $100 \%$ \\
& Aug 2010-Mar 2012 & 158 & $70 \%$ & 52 & $23 \%$ & 16 & $7 \%$ & 226 & $100 \%$ \\
\hline $26-29$ & Apr 2007-Nov 2008 & 194 & $53 \%$ & 141 & $38 \%$ & 32 & $9 \%$ & 367 & $100 \%$ \\
& Dec 2008-Jul 2010 & 255 & $56 \%$ & 178 & $39 \%$ & 22 & $5 \%$ & 455 & $100 \%$ \\
& Aug 2010-Mar 2012 & 176 & $56 \%$ & 119 & $38 \%$ & 20 & $6 \%$ & 315 & $100 \%$ \\
\hline
\end{tabular}

between the age groups $(P=0.434)$, but overall women in this study were more deprived when compared with the national distribution.

Overall, 29\% (524) of cancers were diagnosed between April 2007 and November 2008, 38\% (678) between December 2008 and July 2010 and the remaining 33\% (598) were diagnosed from August 2010 to March 2012. The increase in cancers diagnosed in the middle period is probably because of a large number of women attending screening as a result of the much publicised death from cervical cancer of celebrity Jade Goody in March 2009. The increase in cervical cancer in England in 2009, particularly in women aged 25-39 years, has been noted before (Sasieni and Castanon, 2012).

The age distribution at which women are diagnosed with cervical cancer has changed considerably during the study period. Although the proportion diagnosed at age 20-24 years is currently close to half of what it was at the start of the study $(17 \%$ in the first period $v s 10 \%$ in the last period), the proportion diagnosed at age 25 years has increased almost three-fold (from 13\% to 38\%). In the first period, most women aged 20-29 years were first invited for screening at age 20 years and the number and rate of cervical cancers increased with increasing age (Figure 1A). The age at diagnosis begins to change in the period between December 2008 and July 2010, and there is a noticeable increase in the number and rate of cancers among those aged 25-29 years (Figure 1B). From August 2010 onwards (Figure 1C), when almost all women diagnosed under age 26 years would not have been invited for screening until age 25 years, we see a substantial increase in diagnoses at age 25 years (despite the potential for undercounting because of delays in registration) with a fall in numbers of cancers diagnosed at age 26-29 years. In fact, the rate at age 25 years increases to 41.5 per 100000 (the highest observed during the study period), and between 25.0 and 25.25 the rate peaks at 64.6 per 100000 woman-years. It is also seen that the fall in diagnosed women aged 26-29 years looks to be real in that there is a fall in the rates even after adjusting for the effect of delayed registration. An increase is also observed in women diagnosed between age 24.75 and 25 years because of women who attended and were diagnosed promptly after their first invitation for screening, which is sent out up to 6 months before their 25th birthday. It is not yet possible to observe the effect of changing the age of first invitation on women diagnosed at age 26-29 years because over $75 \%$ were invited for screening at age 20 years.

The effect of the change in screening policy can be seen in the differences in screening history between the age groups (Table 1). Almost half of women diagnosed at age 20-24 years had never 


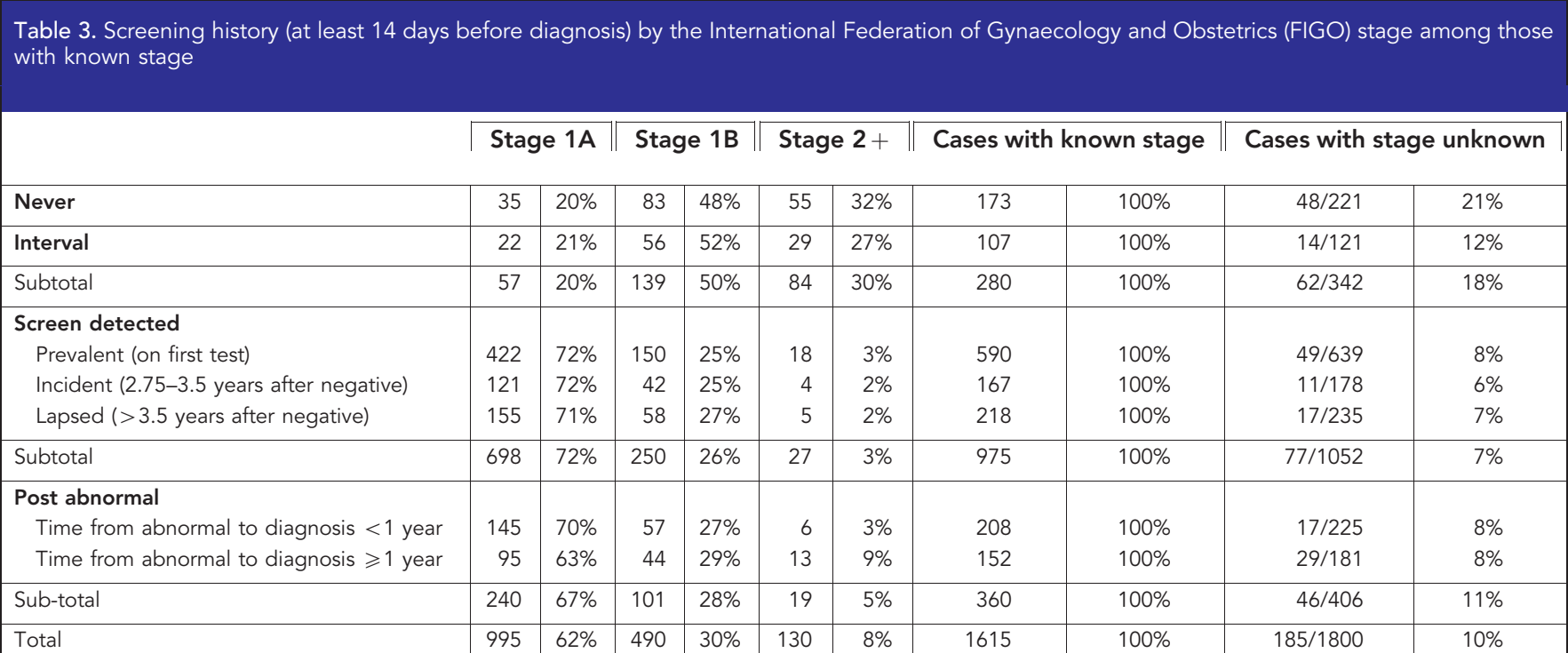

been screened (44\%) compared with $9 \%$ of those aged 25 years and $8 \%$ of those aged 26-29 years. Women aged 25 years at diagnosis were most likely to have been screen detected on their first test $(66 \%)$.

The distribution of FIGO stage at diagnosis in each period is reported in Table 2. An increase in the proportion of stage $1 \mathrm{~B}$ or worse cancers diagnosed at age 20-24 years is seen between the first study period and the last, whereas a decrease in stage $1 \mathrm{~B}+$ cancers is observed in women aged 25 years and no change in the stage distribution is observed for women aged 26-29 years. Changes in the screening histories over the study period are related to the observed changes in the FIGO stage at diagnosis in these young women.

Screening histories by FIGO stage are presented in Table 3. Women who were not screened before diagnosis and those with interval cancers were far more likely to be diagnosed with advanced-stage cancer: $30 \%$ of 280 cancers (with known stage) in this group were stage 2 or worse compared with $3 \%$ of 1335 that were in some sense screen detected (i.e., all the other groups). The unscreened and interval cases were also far less likely to have stage $1 \mathrm{~A}$ cancer $(20 \%$ of 280 cancers were known to be stage $1 \mathrm{~A})$ than the other cases (70\% of 1335 cancers).

\section{DISCUSSION}

The number of cancers diagnosed at age 25 years has changed dramatically over the past few years; rates have increased three-fold since the start of the study period. Cervical cancer is rare in women aged 20-24 years when compared with women aged 25-29 years. Results are distorted by the large proportion of women who are screened and diagnosed at age 25 years: more cancers are diagnosed at age $26(n=257)$ than at ages $20-24$ years combined $(n=223)$. Nevertheless, cancers in women aged 20-24 years tend to be more advanced at diagnosis and of rarer histological types than cancers in older women, leading to more aggressive treatment. Indeed, more women had chemoradiotherapy for cancer diagnosed at age $20-24$ years $(n=58)$ than at age 25 years $(n=29)$. Screen-detected cancers are most likely to be diagnosed as microinvasive cancer (stage 1A), whereas those who were never screened or had interval cancers are most likely to be diagnosed with stage 2 or worse cervical cancer.
This is the largest study of women diagnosed with cervical cancer under the age of 30 years. It includes over $90 \%$ of all cancers at age 20-29 years in England and has complete screening histories. However, it will not be possible to study the full impact of the change in policy on rates of cervical cancer until the first cohort of women invited for screening at age 25 years reach the age of 30 years (around 2015). We cannot disentangle changes in underlying risk factors from changes in the screening policy, both of which are confounded by the Jade Goody effect. Nevertheless, by dividing the study period in three we have been able to show the impact of the change in policy on the age at which cancer is diagnosed.

A weakness of this study is that delays in reporting newly diagnosed cases to the audit mean that the numbers in the most recent period will be underreported. We have taken the view that the timeliness of the data justifies publication even though it is likely to be incomplete. Certainly, the increase in cancers diagnosed at age 25 years (despite the likelihood of underreporting) seems to justify such a decision. We have attempted to adjust the rates taking into account the historical impact of delayed registration.

There are three possible explanations for the increase in cancers observed at age 25 years: (1) cancers are being diagnosed later, that is, cancers that would have been screen detected at age 20-24 years are now diagnosed as stage $1 \mathrm{~A}$ cancers at age 25 years; (2) cancers are not being prevented, that is, women who would have been treated for CIN2/3 at age 20-24 years are now being diagnosed with cancer at age 25 years; (3) cancers are being diagnosed earlier, that is, women who would have been diagnosed with cancer at age 26 or 27 years on their third round of screening are now being diagnosed at age 25 years on their first screening test. It is not possible to say which of these scenarios has played the most prominent role, but our results show no evidence of an increase in $1 \mathrm{~B}$ or worse cervical cancer at age 25 years. Whatever the underlying reasons for the observed changes, results show that $62 \%$ of cancer in women aged 20-29 years were diagnosed as stage $1 \mathrm{~A}$ cancer and of these $94 \%$ (of those with known treatment) were treated with Large loop excision of the transformation zone (LLETZ) or Cone biopsy only. These cases should be considered successes of the programme because they not only have excellent survival (98\% 5-year survival; Kosary, 2007) but also the treatment is essentially the same as would be recommended for women with high-grade cervical intraepithelial neoplasia.

We are unable to distinguish cytology tests taken in response to symptoms from those following an invitation for screening. 
However, the large proportion of advanced stage cancers among women never screened and interval cancers suggest that our screening classification successfully identified those who are most likely to have had symptoms. Nevertheless, women who had cytology taken in response to symptoms may have been included in any of the other categories if the sample was taken more than 14 days before diagnosis.

Studies of cervical cancer in women aged 20-29 in the United Kingdom are few and tend to be small (Rieck et al, 2006; Nair et al, 2007; Herbert et al, 2008; Patel et al, 2012). The combined results for all but the largest study include a total of just 18 cancers (all of which were in women offered screening from age 20 years) diagnosed at age $20-24$ years. Over $60 \%$ of cancers in these studies were stage $1 \mathrm{~A}$ and roughly the same proportions were found to be screen detected. The largest study by Patel et al (2012) included 152 cases aged 20-29 years diagnosed over a 10-year period in the north east (NE) of England. They found a much higher proportion of cancers at age 20-24 years (26\%) than found in this national study (12\%). In 2010, cancers diagnosed at age 20-24 years accounted for just $2 \%$ of all cervical cancers diagnosed in England (Office for National Statistics, 2012).

Patel et al (2012) compared incidence rates between 2000-2002 and 2007-2009 in NE England and concluded there has been an increase in diagnoses of cancer in women under the age of 30 years. However, results were similar for Wales where they continue to screen from age 20 years. The authors concluded that rather than the change in policy, high rates of sexually transmitted infections (STIs) and other underlying risk factors affecting the population of the NE of England are responsible for the increased rates of cervical cancer. This, in addition to the fact that most women in the study of Patel et al (2012) were invited for screening from age 20 years, may account for the differences (described above) in the proportion of women diagnosed at age 20-24 years between studies.

Similarly, Foley et al (2011) reported increasing rates of cervical cancer in England in women under age 40 years, with those born from 1972 onwards at greater risk. Incidence rates since 1975 show rates in women aged $20-24$ years of $\sim 2.1$ per 100000 women from 1975 up until 1999. Between 2000 and 2004, the average rate jumped to 3.0 and it has remained the same in the following 5-year period. Rates in women aged 25-29 years are harder to interpret; during the 1980s, the average rate was 11.3 per 100000 women, between 1990 and 2004 it was 9.6 per 100000 , and it then jumped to 15.8 per 100000 between 2005 and 2009 (Office for National Statistics, 1975-2010). The increase of cervical cancer in women born since 1972 is most likely because of an increase in the underlying risk factors for cervical cancer (rates of STIs, smoking). These trends are concerning, and efforts should be focussed on increasing coverage among women aged 25-29 years rather than on reintroducing screening among those aged 20-24 years. Longerterm HPV vaccination should greatly reduce cervical cancer rates in those born since 1994.

There was concern (Fiander, 2008) that inviting women at age 25 years would lead to a drop in coverage in those under age 30 years. Latest statistics show that 3-yearly coverage in those aged 25-29 years has remained roughly the same ( 62\%) from 2002 to 2012 (screening programme stats 2011/12). Nevertheless, it is low compared with coverage among those aged $30-49$ years $(71 \%$ on average).

Results presented here show that most cancers diagnosed at age 20-29 years are screen detected microinvasive cancer (stage 1A) with excellent prognosis. As a result of the change in policy, there has been a shift in the age at which women are diagnosed; since August 2010, half of all cancers in this age group have been diagnosed at age 25 years. Although cancer at age 20-24 years tends to be diagnosed at more advanced stages, it is rare in this age group.

\section{ACKNOWLEDGEMENTS}

This work is supported by Cancer Research UK (C8162/10406 and C8162/12537).

\section{CONFLICT OF INTEREST}

The authors declare no conflict of interest.

\section{ETHICAL APPROVAL}

The collection of data as part of this audit has been covered since 2003 by section 251 of the NHS Act 2006 re-enacted Section 60 of the Health and Social Care Act 2001 approval (PIAG 1-08(a)/ 2003). The analysis of anonymised data in this context is considered service evaluation that does not require research ethics approval according to the UK guidelines (NRES) (National Patient Safety Agency, 2009).

\section{DISCLAIMER}

The funder had no input in the analysis or interpretation of the data or the writing of the paper. The corresponding author had full access to all the data in the study and had final responsibility for the decision to submit for publication.

\section{REFERENCES}

Cancer Research UK (2010) CANCERSTATS: Cervical Cancer - UK incidence statistics. European Age-Standardised Incidence Rates per 100,000 Population, by Age, Females, UK 1993-2009 [Online]. Available: http:// www.cancerresearchuk.org/cancer-info/cancerstats/types/cervix/ incidence/\#world(Accessed 05 March 2013).

Department for Communities and Local Government (2011) English Indices of Deprivation 2010: Technical Report England, Available https://www.gov. uk/government/publications/english-indices-of-deprivation-2010technical-reporthttp://www.communities.gov.uk/publications/ communities/indiciesdeprivation 07 .

Department of Health (2010) Clinical practice guidelines for the assessment of young women aged 20-24 with abnormal vaginal bleeding. Available http:// www.dh.gov.uk/en/Publicationsandstatistics/Publications/Publications PolicyAndGuidance/DH_113478.

Fiander AN (2008) Cervical screening in young women aged 20-24 years. J Fam Plann Reprod Health Care 34: 19.

Foley G, Alston R, Geraci M, Brabin L, Kitchener H, Birch J (2011) Increasing rates of cervical cancer in young women in England: an analysis of national data 1982-2006. Br J Cancer 105: 177-184.

Health and Social Care Information Centre. S. A. I (2012) Cervical screening programme England, 2011/12. Available: http://www.cancerscreening. nhs.uk/cervical/statistics-bulletin.html.

Herbert A, Holdsworth G, Kubba AA (2008) Cervical screening: why young women should be encouraged to be screened. J Fam Plann Reprod Health Care 34: 21-25.

Kosary CL (2007) Cancer of the Cervix Uteri. In SEER Survival Monograph: Cancer Survival Among Adults: U.S. SEER Program, 1988-2001, Patient and Tumor Characteristics, Ries LAG, Young JL, Keel GE, Eisner MP, LIn YD, Horner M-J (eds) (National Cancer Institute, SEER Program: Bethesda, MD, NIH Pub No. 07-6215).

Nair MS, Bhandari HM, Nordin AJ (2007) Cervical cancer in women aged less than 25: East Kent experience. J Obstet Gynaecol 27: 706-708.

National Patient Safety Agency (2009) NRES Leaflet: Defining research. [Online]. Available http://www.nres.nhs.uk/applications/is-your-projectresearch/.

Office for National Statistics (1975-2010) Cancer statistics registrations, England (Series MB1). Dataset prepared by Cancer Research UK: London, 
Available http://www.ons.gov.uk/ons/search/index.html?newquery=series + mbl.

Office for National Statistics (2012) Cancer statistics registrations. Registrations of cancer diagnosed in 2010, England. London, Available http://www.ons.gov.uk/ons/publications/index.html?pageSize $=50$ \&newquery=Cancer + Statistics + Registrations $\% 2 C+$ England + $($ Series + MB1 $) \&$ sortBy=pubdate\&sortDirection=DESCENDING\& content-type $=$ publicationContent $\mathrm{Types} \&$ pubdateRangeType $=$.

Office for National Statistics (2013) Population Estimates for England and Wales, single year of age unformatted - Mid 2006 to Mid 2011 Revised (Subnational). Available http://www.ons.gov.uk/ons/publications/ re-reference-tables.html?edition=tcm\%3A77-280885.

Patel A, Galaal K, Burnley C, Faulkner K, Martin-Hirsch P, Bland MJ, Leeson S, Beer H, Paranjothy S, Sasieni P, Naik R (2012) Cervical cancer incidence in young women: a historical and geographic controlled UK regional population study. Br J Cancer 106: 1753-1759.

PHLS Communicable Disease Surveillance Centre (2006a) Increasing rates of Chlamydia trachomatis and the role of screening [Online]. Available http:// www.hpa.org.uk/CDR/archives/archive06/hiv_STIs06.htm

[Accessed 12 October 2012].

PHLS Communicable Disease Surveillance Centre (2006b) Recent trends in gonorrhoea in England, Wales and Northern Ireland [Online]. Available http://www.hpa.org.uk/CDR/archives/archive06/hiv_STIs06.htm [Accessed 12 October 2012].
Rieck GC, Tristram A, Hauke A, Fielder H, Fiander AN (2006) Cervical screening in 20-24-year olds. J Med Screen 13: 64-71, discussion 62-3.

Sargent A, Bailey A, Almonte M, Turner A, Thomson C, Peto J, Desai M, Mather J, Moss S, Roberts C, Kitchener HC, ARTISTIC Study Group (2008) Prevalence of type-specific HPV infection by age and grade of cervical cytology: data from the ARTISTIC trial. Br J Cancer 98: 1704-1709.

Sasieni P, Adams J, Cuzick J (2003) Benefit of cervical screening at different ages: evidence from the UK audit of screening histories. Br J Cancer 89: 88-93.

Sasieni P, Castanon A (2012) Dramatic increase in cervical cancer registrations in young women in 2009 in England unlikely to be due to the new policy not to screen women aged 20-24. J Med Screen 19: $127-132$.

Sasieni P, Castanon A, Cuzick J (2009) Effectiveness of cervical screening with age: population based case-control study of prospectively recorded data. BMJ 339: b2968.

(c) (i) (2) (2) This work is licensed under the Creative Commons AY NG SA Attribution-NonCommercial-Share Alike 3.0 Unported License. To view a copy of this license, visit http://creativecommons. org/licenses/by-nc-sa/3.0/

APPENDIX 1

Table A1. Screening history classification

\begin{tabular}{|c|c|c|c|c|c|c|c|c|c|c|}
\hline & & \multicolumn{3}{|c|}{ No early recall } & \multicolumn{3}{|c|}{ Early recall $=$ gap $<1$ year } & \multicolumn{3}{|c|}{ Early Recall $=$ gap $\geqslant 1$ year } \\
\hline \multicolumn{2}{|c|}{ Time from last suspend to diagnosis } & None & $\begin{array}{c}\leqslant 4 \\
\text { Months }\end{array}$ & $\begin{array}{c}>4 \\
\text { Months }\end{array}$ & None & $\begin{array}{c}\quad \leqslant 4 \\
\text { Months }\end{array}$ & $\begin{array}{c}>4 \\
\text { Months }\end{array}$ & None & $\begin{array}{c}\leqslant 4 \\
\text { Months }\end{array}$ & $>4$ Months \\
\hline \multirow{4}{*}{$\begin{array}{l}\text { Time from last routine } \\
\text { test to early recall, } \\
\text { suspend or diagnosis, } \\
\text { whichever comes first }\end{array}$} & None & $\begin{array}{c}N=212 \\
\text { Never }\end{array}$ & $\begin{array}{l}N=614 \\
\text { Screen } \\
\text { detected } \\
(\mathrm{SD}) \text { on } \\
\text { first test }\end{array}$ & $\begin{array}{c}N=127 \\
\text { Post } \\
\text { abnormal }\end{array}$ & $\begin{array}{c}N=3 \\
\text { Post } \\
\text { abnormal }\end{array}$ & $\begin{array}{l}N=25 \\
S D \text { on } \\
\text { first test }\end{array}$ & $\begin{array}{c}N=16 \\
\text { Post } \\
\text { abnormal }\end{array}$ & $\begin{array}{c}N=9 \\
\text { Post } \\
\text { abnormal }\end{array}$ & $\begin{array}{c}N=46 \\
\text { Post } \\
\text { abnormal }\end{array}$ & $\begin{array}{c}N=31 \\
\text { Post } \\
\text { abnormal }\end{array}$ \\
\hline & $\begin{array}{l}>3.5 \\
\text { years }\end{array}$ & $\begin{array}{l}N=23 \\
\text { Lapsed }\end{array}$ & $\begin{array}{c}N=223 \\
\text { SD lapsed }\end{array}$ & $\begin{array}{c}N=49 \\
\text { Post } \\
\text { abnormal }\end{array}$ & $\begin{array}{c}N=0 \\
\text { Lapsed }\end{array}$ & $\begin{array}{c}N=23 \\
\text { SD lapsed }\end{array}$ & $\begin{array}{c}N=7 \\
\text { Post } \\
\text { abnormal }\end{array}$ & $\begin{array}{c}N=3 \\
\text { Post } \\
\text { abnormal }\end{array}$ & $\begin{array}{c}N=7 \\
\text { Post } \\
\text { abnormal }\end{array}$ & $\begin{array}{c}N=6 \\
\text { Post } \\
\text { abnormal }\end{array}$ \\
\hline & $\begin{array}{c}2.75-3.5 \\
\text { years }\end{array}$ & $\begin{array}{l}N=24 \\
\text { Interval }\end{array}$ & $\begin{array}{c}N=176 \\
\mathrm{SD} \\
\text { incidence }\end{array}$ & $\begin{array}{c}N=29 \\
\text { Post } \\
\text { abnormal }\end{array}$ & $\begin{array}{c}N=2 \\
\text { Interval }\end{array}$ & $\begin{array}{c}N=14 \\
\text { SD } \\
\text { incidence }\end{array}$ & $\begin{array}{c}N=8 \\
\text { Post } \\
\text { abnormal }\end{array}$ & $\begin{array}{c}N=2 \\
\text { Post } \\
\text { abnormal }\end{array}$ & $\begin{array}{c}N=5 \\
\text { Post } \\
\text { abnormal }\end{array}$ & $\begin{array}{c}N=7 \\
\text { Post } \\
\text { abnormal }\end{array}$ \\
\hline & $\begin{array}{l}<2.75 \\
\text { years }\end{array}$ & $\begin{array}{l}N=64 \\
\text { Interval }\end{array}$ & $\begin{array}{l}N=27 \\
\text { Interval }\end{array}$ & $\begin{array}{c}N=2 \\
\text { Interval }\end{array}$ & $\begin{array}{c}N=0 \\
\text { Interval }\end{array}$ & $\begin{array}{c}N=1 \\
\text { Interval }\end{array}$ & $\begin{array}{c}N=0 \\
\text { Interval }\end{array}$ & $\begin{array}{l}N=0 \\
\text { Interval }\end{array}$ & $\begin{array}{l}N=0 \\
\text { Interval }\end{array}$ & $\begin{array}{c}N=0 \\
\text { Interval }\end{array}$ \\
\hline
\end{tabular}

